Article

\title{
Production and Use of Recombinant Profilins Amb a 8, Art v 4, Bet v 2, and Phl p 12 for Allergenic Sensitization Studies
}

\author{
Beata Cudowska ${ }^{1}$, A. Brenda Kapingidza ${ }^{2}$, Magdalena Pawłowicz ${ }^{1}$, Agnieszka Pampuch ${ }^{3}$, \\ Noah Hyduke ${ }^{2}$, Swanandi Pote ${ }^{2}$, Caleb R. Schlachter ${ }^{2}$, Dariusz M. Lebensztejn ${ }^{1}$, \\ Maksymilian Chruszcz ${ }^{2, *}$ (i) and Krzysztof Kowal ${ }^{3,4, *}$ \\ 1 Department of Pediatrics, Gastroenterology, Hepatology, Nutrition and Allergology, Medical University of \\ Bialystok, 15-276 Bialystok, Poland; beata.cudowska@umb.edu.pl (B.C.); \\ magdalena_pawlowicz@o2.pl (M.P.); lebensztejn@hoga.pl (D.M.L.) \\ 2 Department of Chemistry and Biochemistry, University of South Carolina, Columbia, SC 29208, USA; \\ anyway@email.sc.edu (A.B.K.); nhyduke@email.sc.edu (N.H.); swanandi@gmail.com (S.P.); \\ schlachc@gmail.com (C.R.S.) \\ 3 Department of Allergology and Internal Medicine, Medical University of Bialystok, 15-276 Bialystok, Poland; \\ agapam@o2.pl \\ 4 Department of Experimental Allergology and Immunology, Medical University of Bialystok, \\ 15-276 Bialystok, Poland \\ * Correspondence: chruszcz@mailbox.sc.edu (M.C.); kowalkmd@umb.edu.pl (K.K.); \\ Tel.: +1-803-777-7399 (M.C.); +48-85-6865153 (K.K.)
}

Received: 19 December 2019; Accepted: 13 January 2020; Published: 16 January 2020

check for updates

\begin{abstract}
Four recombinant (r) allergens (rAmb a 8.0101, rArt v 4.0101, rBet v 2.0101, and rPhl p 12.0101) were successfully produced and used for sensitization studies. The allergens belong to the profilin family which is one of the most numerous allergen families. These four proteins represent allergens originating from pollen of weeds (rAmb a 8.0101 and rArt v 4.0101), tree (rBet v 2.0101) and grass ( $\mathrm{rPhl} \mathrm{p}$ 12.0101). The recombinant allergens were characterized using various biochemical and biophysical methods and tested for their ability to bind patient-derived antibodies. One hundred patients aged 2 to 50 years sensitized to pollen and plant-derived food allergens ( $\operatorname{IgE}>0.35 \mathrm{kU} / \mathrm{L}$ ) were included. Sensitization to individual allergen sources and components of birch and timothy pollens was evaluated using multiparameter immunoblots. The presence of IgE to pollen-derived recombinant profilins $\mathrm{rAmb}$ a 8.0101, rArt v 4.0101, rBet v 2.0101, and rPhl p 12.0101 in serum was evaluated using ELISA method. The presence of IgE against pollen profilins was detected in 20 out of 100 studied patients. High correlation was seen between IgE ELISA results with individual pollen profilins. In summary, it was shown that the recombinant versions of the four allergenic profilins can be used for sensitization studies and for component-resolved allergy diagnostics.
\end{abstract}

Keywords: recombinant allergen; IgE; pollen-food allergy; profilin

\section{Introduction}

Profilins are ubiquitous, small proteins ranging between $12-16 \mathrm{kDa}$ that are expressed in all eukaryotic cells and certain viruses, with the exception of some protists [1,2]. Profilins play a role in regulating various cellular processes like membrane trafficking, actin cytoskeletal dynamics, and they bind to proline-rich regions of proteins (Figure 1) [3]. The profilin family shares highly conserved amino acid sequences, even among distantly related sources [4]. This also holds true for profilins derived from different plants that are highly similar to each other, sharing approximately $80 \%$ amino 
acid identity [4]. This renders them as panallergens, but minor allergens widespread in pollens and foods, and responsible for immunoglobulin E (IgE) cross-reactivity [5]. Moreover, structural and immunological analyses of profilins indicate that profilins present in pollens and plant-derived foods are highly cross-reactive [4]. These proteins usually act as respiratory allergens producing mild allergic symptoms [6,7].
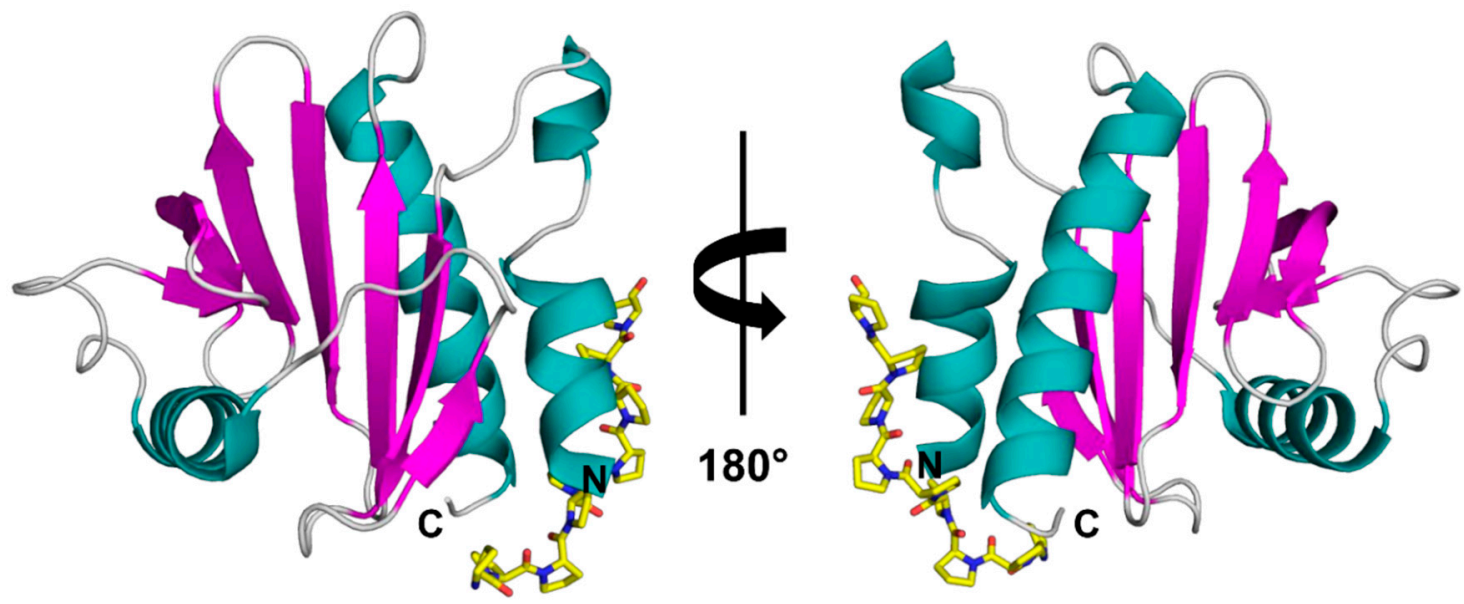

Figure 1. Crystal structure of rArt v 4.0101 (PDB code: 5EM0) with modelled poly(L-Pro). The structure is shown in two different orientations with secondary structure elements colored ( $\alpha$-helices-teal, $\beta$-strands-purple, loops-grey). The poly(L-Pro) is shown in yellow stick representation.

Under certain circumstances, however, they may be responsible for food-derived allergy symptoms including systemic anaphylaxis [6-8]. A broad range of plant-derived food products contain profilins, including fruits, legumes, nuts, and vegetables [1,4]. It is commonly accepted, however, that profilin-dependent allergic reactions to food result from cross-reactivity between pollen and food profilins where the former are true sensitizers [6,7]. Although some profilins can elicit adverse immune responses like anaphylaxis, the infrequent systemic reactions observed in patients after oral exposure to profilins is due to their low stability and high susceptibility to denaturation by proteases and the acidic environment in the digestive tract $[9,10]$.

Profilins represent one of the most numerous allergen families that are associated with many clinical syndromes, including pollen-food syndrome discussed above [11]. Of particular interest are profilins emanating from weed pollens, plants, and grass that play a major role in eliciting seasonal allergies [12]. In this research, four profilins, two from weeds (Amb a 8 and Art v 4), one from trees (Bet v 2), and one from grass (Phl p 12), were studied (Figure 2). Amb a 8 originates from short ragweed (Ambrosia artemisiifolia), and Art v 4 originates from mugwort (Artemisia vulgaris). Although the Asteraceae family is comprised of thousands of plant species, Ambrosia (ragweed) and Artemisia (mugwort) are among the most important sources of profilins [12]. Mugwort is a member of the Asteraceae family found in the northern hemisphere, the Mediterranean basin, and parts of Asia [13]. In late summer and autumn, mugwort pollen is primarily responsible for allergic reactions in patients with mugwort allergy [2]. Specifically in Europe, Art v 4 has a sensitizing prevalence of 34-36\% [12]. In late summer and early fall, ragweed elicits type 1 allergic immune responses in more than 15 million patients in just the USA and Canada [12]. Amb a 8 has high amino acid sequence identity (89\%) and similarity (92\%) when compared to Art v 4 (Figure 2), which implicates a very high likelihood of cross reactivity according to the A-RISC index [4].

Bet v 2 (birch pollen allergen) was the first profilin shown to be an allergen [14]. It is a $15 \mathrm{kDa}$ protein originating from Betula pendula also known as the European white birch. Of the 242 birch pollen-sensitized patients from six European countries, 22\% recognized Bet v 2 by IgE antibody production [14]. Like most profilins, this qualifies Bet v 2 as a minor allergen. Although a minor allergen, Bet v 2 plays a major role in IgE cross-reactivity between plants and food [15]. On the other 
hand, Phl p 12 originates from Phleum pratense, Timothy grass, a perennial grass native to most of Europe and found mainly in the Pacific Northwest, the Northeast, and Midwest of the United States. Due to this ubiquitous nature of Timothy grass, it is a potent source of allergens for many patients sensitized to the grass. Despite Phl p 12's characterization as a minor allergen, it displays comparable $\mathrm{T}$ cell response prevalence and strength as $\mathrm{Phl} \mathrm{p} \mathrm{1}$, a major allergen from P. pratense [16]. In addition, it is released from Timothy pollen in the same timeframe as the other Timothy grass allergens and in similar amounts as the major allergen, Phl p 1 [16].
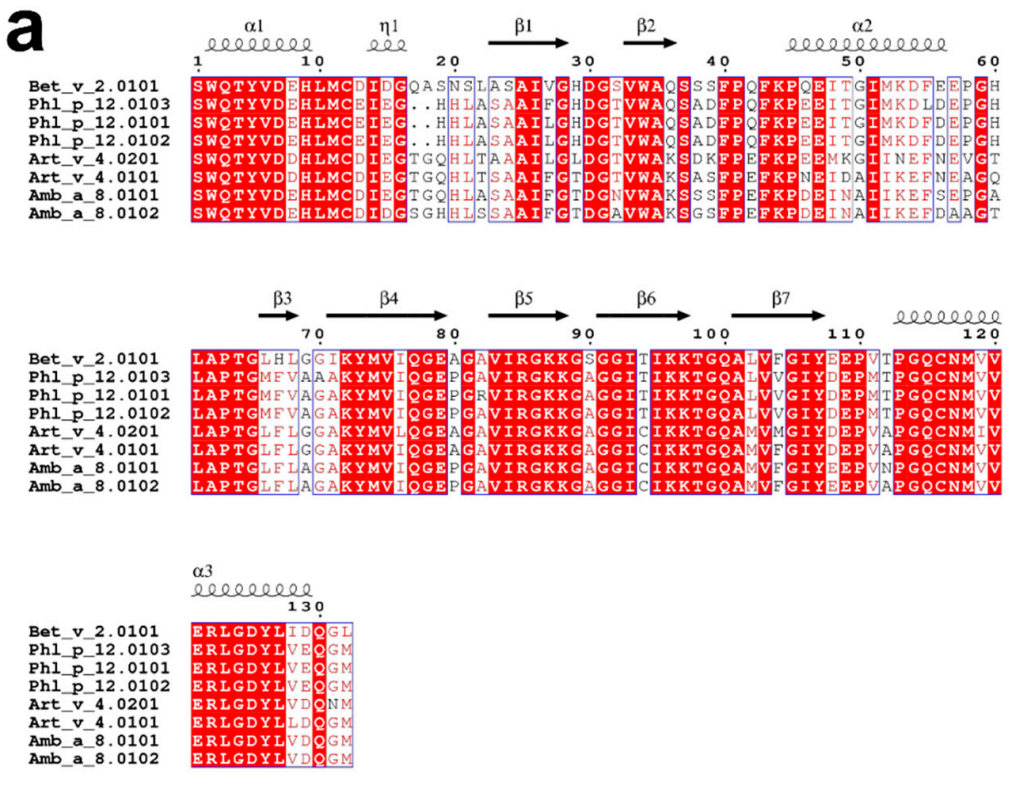

b

\begin{tabular}{|c|c|c|c|c|c|c|c|c|}
\hline Bet $\vee 2.0101$ & $100 \%$ & & & & \multirow{2}{*}{\multicolumn{4}{|c|}{ Sequence identity }} \\
\hline Phl p 12.0103 & $78 \%$ & $100 \%$ & & & & & & \\
\hline Phl p 12.0101 & $78 \%$ & $97 \%$ & $100 \%$ & & & & & \\
\hline Phl p 12.0102 & $79 \%$ & $98 \%$ & $99 \%$ & $100 \%$ & & & & \\
\hline Art v 4.0201 & $71 \%$ & $74 \%$ & $75 \%$ & $76 \%$ & $100 \%$ & & & \\
\hline Art v 4.0101 & $75 \%$ & $78 \%$ & $78 \%$ & $78 \%$ & $87 \%$ & $100 \%$ & & \\
\hline Amb a 8.0101 & $77 \%$ & $80 \%$ & $80 \%$ & $81 \%$ & $82 \%$ & $89 \%$ & $100 \%$ & \\
\hline Amb a 8.0102 & $75 \%$ & $78 \%$ & $78 \%$ & $79 \%$ & $80 \%$ & $88 \%$ & $92 \%$ & $100 \%$ \\
\hline & 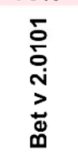 & 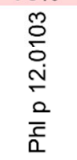 & $\begin{array}{l}5 \\
\vdots \\
\stackrel{0}{N} \\
\frac{0}{c} \\
\frac{1}{2}\end{array}$ & 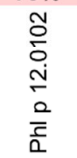 & 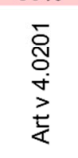 & $\begin{array}{l}5 \\
\\
\\
\dot{+} \\
\frac{1}{4}\end{array}$ & $\begin{array}{l}5 \\
0 \\
0 \\
\infty \\
\pi \\
0 \\
\text { है }\end{array}$ & 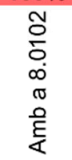 \\
\hline
\end{tabular}

\begin{tabular}{|c|c|c|c|c|c|c|c|c|}
\hline Bet $\vee 2.0101$ & $100 \%$ & & & & \multirow{2}{*}{\multicolumn{4}{|c|}{ Sequence similarity }} \\
\hline Phl p 12.0103 & $84 \%$ & $100 \%$ & & & & & & \\
\hline Phl p 12.0101 & $85 \%$ & $97 \%$ & $100 \%$ & & & & & \\
\hline Phl p 12.0102 & $86 \%$ & $98 \%$ & $99 \%$ & $100 \%$ & & & & \\
\hline Art $\vee 4.0201$ & $78 \%$ & $79 \%$ & $81 \%$ & $82 \%$ & $100 \%$ & & & \\
\hline Art v 4.0101 & $80 \%$ & $82 \%$ & $82 \%$ & $83 \%$ & $89 \%$ & $100 \%$ & & \\
\hline Amb a 8.0101 & $79 \%$ & $85 \%$ & $85 \%$ & $85 \%$ & $86 \%$ & $92 \%$ & $100 \%$ & \\
\hline Amb a 8.0102 & $77 \%$ & $84 \%$ & $84 \%$ & $85 \%$ & $86 \%$ & $92 \%$ & $93 \%$ & $100 \%$ \\
\hline & 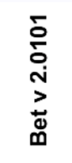 & $\begin{array}{l}\stackrel{\Re}{0} \\
\frac{0}{0} \\
\stackrel{1}{\circ} \\
\frac{0}{c} \\
\frac{1}{\alpha}\end{array}$ & 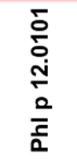 & $\begin{array}{l}\text { Õ } \\
\frac{0}{0} \\
\stackrel{+}{a} \\
\frac{0}{c} \\
\frac{1}{\alpha}\end{array}$ & 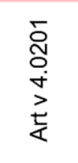 & $\begin{array}{l}5 \\
\text { O } \\
\dot{+} \\
> \\
\frac{1}{4}\end{array}$ & $\begin{array}{l}5 \\
\vdots \\
\infty \\
\infty \\
\pi \\
0 \\
\frac{0}{\alpha}\end{array}$ & 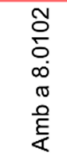 \\
\hline
\end{tabular}

Figure 2. Comparison of Amb a 8, Art v 4, Bet v 2, and Phl p 12 sequences. All isoallergens reported by the World Health Organization (WHO) and International Union of Immunological Societies (IUIS) Allergen Nomenclature Sub-committee (allergen.org) are shown. (a) Sequence alignment generated using Clustal Omega [17] and ESPript [18]. (b) Sequence identities and similarities between the profilins as calculated by SIAS (http://imed.med.ucm.es/Tools/sias.html) using the default parameters. 
The main scope of this research was to produce the recombinant versions of Amb a 8.0101, Art v 4.0101, Bet v 2.0101, and Phl p 12.0101, characterize the molecular and physical properties of these profilins, and finally test their sensitizing patterns in children and adult patients from North-East Poland. The region is abundant in birch, grass, and mugwort, but no ragweed is to be found. Consequently, studying the molecular and immunological characteristics of Amb a 8, Art v 4, Bet v 2, and Phl p 12 will clarify the clinical relevance of these important profilins in allergy sensitization and their possible contribution to pollen-food syndrome.

\section{Results}

\subsection{Protein Production and Thermal Stability}

The yield of recombinant Phl p 12.0101 production was approximately $70 \mathrm{mg}$ of protein per $1 \mathrm{~L}$ of Escherichia coli culture. Protein recovery after cleavage of the purification tag by TEV protease was observed to be about 70\%. SDS-PAGE confirmed the purity of the protein to be $>98 \%$. The protein was purified in monomeric form and mass spectrometry (results not shown) confirmed the expected molecular weight for this quaternary structure. The final yield of the $\mathrm{rPhl} \mathrm{p} 12.0101$ production is approximately two-fold higher when compared with the yield of production of rAmb a 8.0101, rArt v 4.0101, rBet v 2.0101, and rCuc m 2.0101 [2,10].

For the thermal stability of $\mathrm{rPhl} \mathrm{p}$ 12.0101, the DSF results performed show that the protein without purification tag was more stable with $\mathrm{T}_{\mathrm{m}}$ difference as high as $6{ }^{\circ} \mathrm{C}$ than with the tag intact (Figure 3a). Both versions of the protein, however, are most stable between pH 5.0 to 8.5 and least stable between $\mathrm{pH} 4.0$ to 4.5. Salt concentration does not have a major impact on $\mathrm{rPhl} \mathrm{p} 12.0101$ thermal stability, and the only exemption is seen at $1 \mathrm{M} \mathrm{NaCl}$ for the protein with the purification tag.
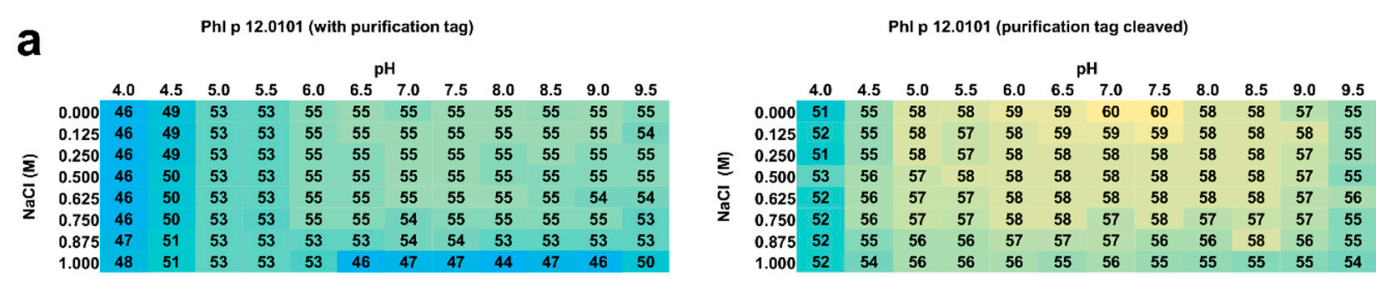

b Phl p 12.0101 vs. Amb a 8.0101 (with purification tag)
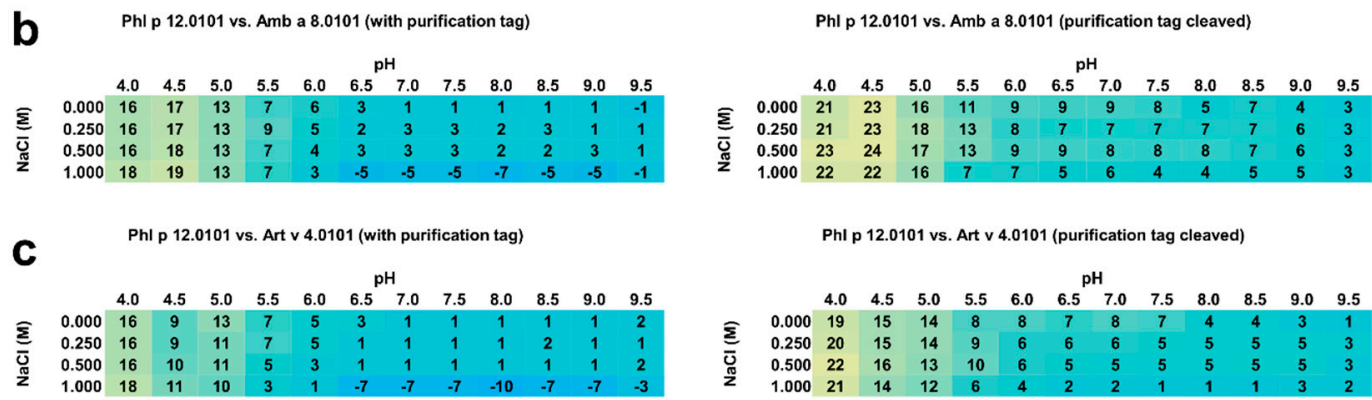

$\mathbf{C}$
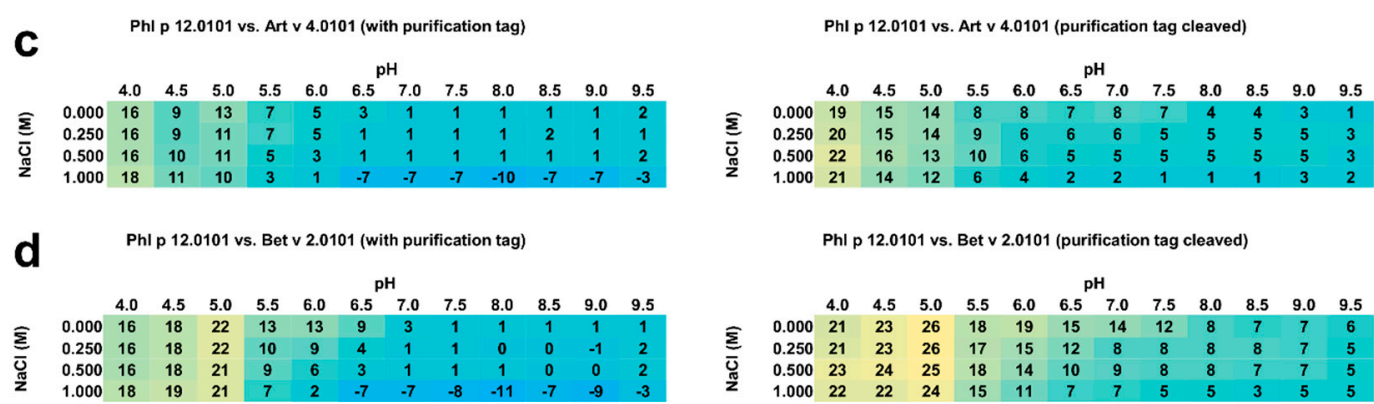

Figure 3. (a) Average melting temperatures $\left(\mathrm{T}_{\mathrm{m}}\right.$ in $\left.{ }^{\circ} \mathrm{C}\right)$ for $\mathrm{rPhl} \mathrm{p} 12.0101$ with and without purification tag. Yellow and blue represent high and low melting temperatures, respectively. (b) Melting temperature $\left(\mathrm{T}_{\mathrm{m}}\right.$ in ${ }^{\circ} \mathrm{C}$ ) differences between $\mathrm{rPhl} \mathrm{p} 12.0101$ and $\mathrm{rAmb}$ a 8.0101. (c) Melting temperature differences between $\mathrm{rPhl} \mathrm{p} 12.0101$ and rArt v 4.0101. (d) Melting temperature differences between $\mathrm{rPhl} \mathrm{p} 12.0101$ and rBet v 2.0101. Yellow and blue represent high and low differences in the melting temperatures, respectively. The standard deviation for the presented values was less than $1^{\circ} \mathrm{C}$ for all experiments. 
Generally, in comparison with rAmb a 8.0101, rArt v 4.0101, and rBet v 2.0101, rPhl p 12.0101 without purification tag is more stable than all the other three profilins (Figure $3 b-d$ ). However, the timothy grass profilin is significantly more stable in solutions with lower $\mathrm{pH}$ values both with and without the purification tag. For example, when $\mathrm{rPhl}$ p 12.0101 is compared to the other three profilins, the protein is clearly more stable in the 4.0 to $6.0 \mathrm{pH}$ range, and the differences are especially pronounced in solutions with $\mathrm{pH}$ between 4.0 and 5.5. In these conditions, $\mathrm{rPhl} \mathrm{p} 12.0101 \mathrm{has} \mathrm{T}_{\mathrm{m}}$ 7-26 ${ }^{\circ} \mathrm{C}$ higher in comparison with $\mathrm{rAmb}$ a 8.0101, rArt v 4.0101, and rBet v 2.0101 (Figure 3b-d). The biggest differences are observed for solutions with $\mathrm{pH}$ range 4.0 to 5.0. On the other hand, $\mathrm{rPhl}$ $\mathrm{p} 12.0101$ with the purification tag is nearly as stable as the other three profilins from $\mathrm{pH} 7.0$ to 9.5. Interestingly, at $1 \mathrm{M}$ salt concentration, $\mathrm{rPhl} \mathrm{p} 12.0101$ with purification tag is significantly less stable than rAmb a 8.0101, rArt v 4.0101, and rBet v 2.0101 with $\mathrm{T}_{\mathrm{m}}$ difference as high as $11^{\circ} \mathrm{C}$ (Figure 3d).

\subsection{Spectroscopy}

The secondary structure for Phl p 12 was determined by CAPITO software based on CD spectroscopy data. The secondary structure for the protein was estimated as follows (according to similarity hits based on 25 nearest neighbors): $\alpha$-helices $9-16 \%$, $\beta$-strands $32-48 \%$, and random coils (irregular) 42-58\% [19]. These results are very similar to the secondary structure calculated using the crystal structure of another profilin reported previously, Cuc $\mathrm{m} 2.0101$ [10], and in addition, the CD spectra for $\mathrm{rPhl} \mathrm{p} 12.0101$ is very similar to that recorded for Cuc $\mathrm{m} 2$. These data strongly suggest that the $\mathrm{rPhl} \mathrm{p} 12.0101$ is properly folded.

\subsection{Profilin Sensitization}

Sensitization to profilins was demonstrated in $20(\mathrm{P}+)$ out of 100 pollen and/or food-allergensensitized subjects, as determined by the commercial component multiblot. There were $9 \mathrm{P}+$ among 50 studied children (18\%) and $11 \mathrm{P}+$ among 50 studied adults $(22 \%)$. Similar results were obtained in the IgE ELISA. The mean absorbances of IgE ELISA with individual pollen profilins rAmb a 8.0101, rArt v 4.0101, rBet v 2.0101, and rPhl p 12.0101 in P+ were significantly greater than those in P(Figure 4). The results of IgE ELISA with rBet v 2.0101 and $\mathrm{rPhl} p 12.0101$ significantly correlated with the corresponding results of multiparameter immunoblots ( $\mathrm{r}=0.895 ; 95 \%$ CI 0.75 to $0.958, p<0.0001$ and $r=0.906 ; 95 \%$ CI 0.775 to $0.963, p<0.0001$, respectively) (Figure 5).

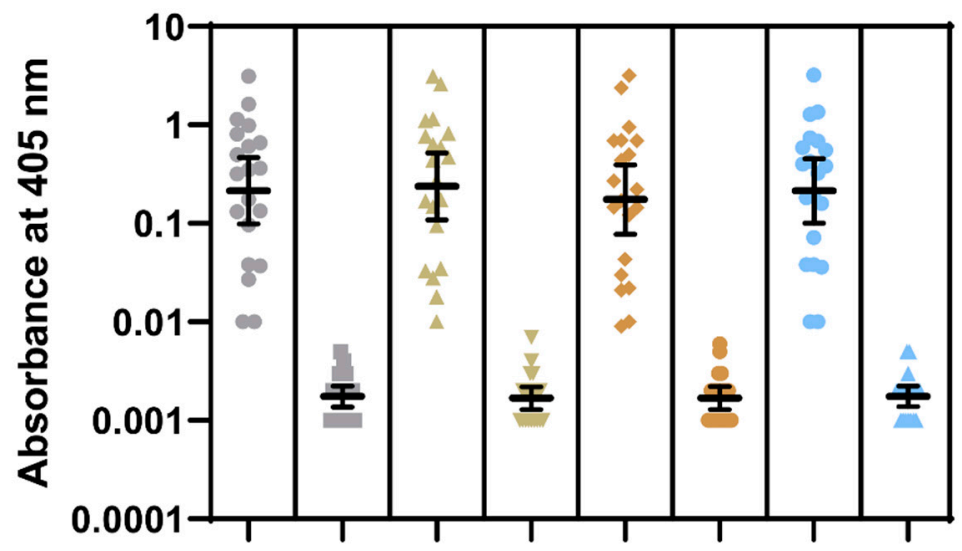

- $A m b$ a 8

- Control Amb a 8

$\triangle \quad$ Art v 4

v Control Art v 4

- Bet v 2

- Control Bet v 2

- $\quad$ Phl p 12

$\triangle \quad$ Control Phl p 12

Figure 4. IgE ELISA results to recombinant Amb a 8.0101, Art v 4.0101, Bet v 2.0101, and Phl p 12.0101. Geometric means with 95\% CI are marked. 

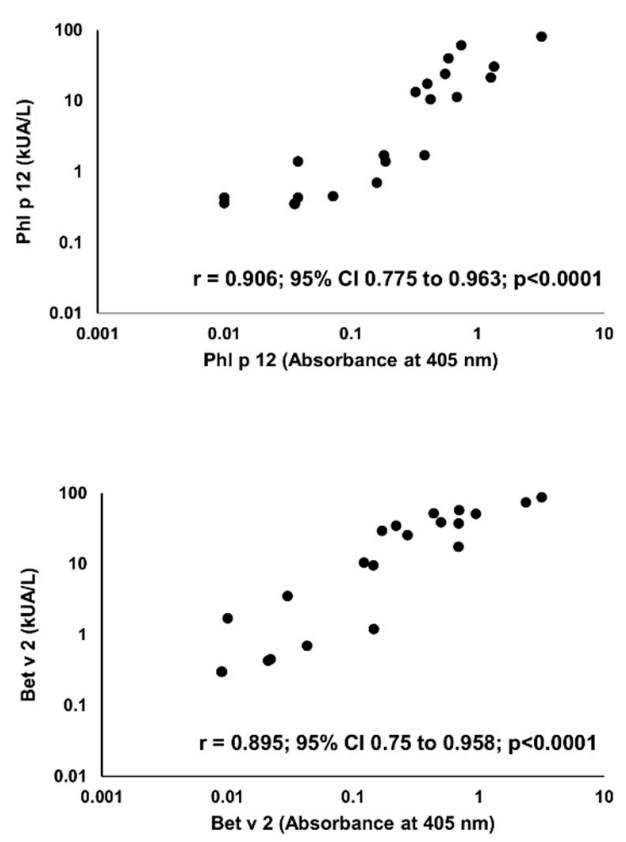

Figure 5. Correlation between IgE ELISA (X-axis) and multiparameter immunoblot (Y-axis) results for Phl p 12 (upper panel) and Bet v 2 (lower panel).

In each of $\mathrm{P}+$ patients, IgE reactivity to all four studied profilins (rAmb a 8.0101, rArt v 4.0101, rBet $\mathrm{v}$ 2.0101, and $\mathrm{rPhl} \mathrm{p}$ 12.0101) was found. Significant correlations were seen between the IgE ELISA results with each individual profilin (Figure 6).
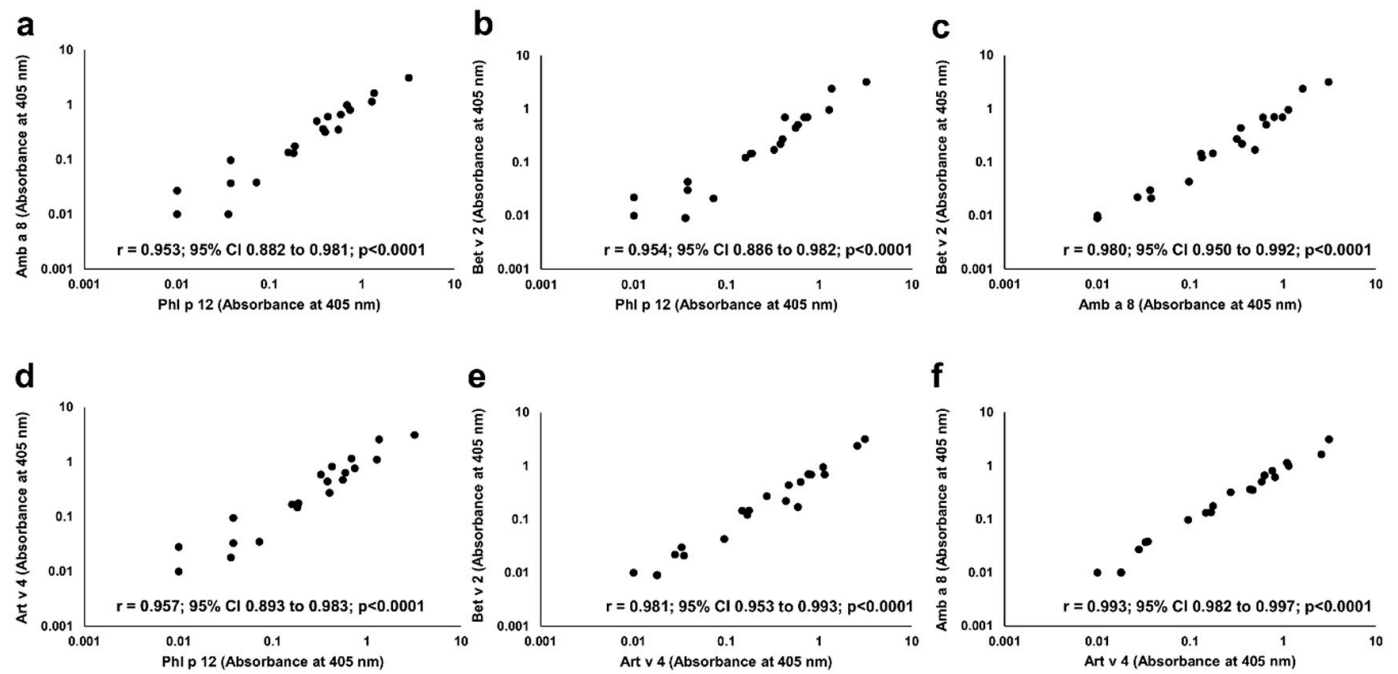

Figure 6. Correlation between IgE binding to individual recombinant profilins. Pairwise comparison of IgE ELISA results performed with Amb a 8 (a,c,f), Art v 4 (d,e,f), Bet v 2 (b, c, e) and Phl p 12 (a,b,d) is depicted on individual charts.

The intensity of IgE binding to individual recombinant profilins was different among P+ patients. The greatest intensity of IgE binding to Phl p 12.0101 was demonstrated in 7 of 20 (35\%) P+ patients including four children and three adults, and to Art v 4.0101 in 6 of $20(30 \%) \mathrm{P}+$ patients including three children and three adults. The results were supported by inhibition ELISA (Figure 7). Complete inhibition of IgE binding exclusively by Phl p 12.0101 and Art v 4.0101 was demonstrated in 7 of 20 $(35 \%)$ and 6 of $20(30 \%) \mathrm{P}+$ patients, respectively (Figure 7$)$. However, in seven patients (five adults and two children), no clear dominance of IgE reactivity to a single profilin could be demonstrated. 
a

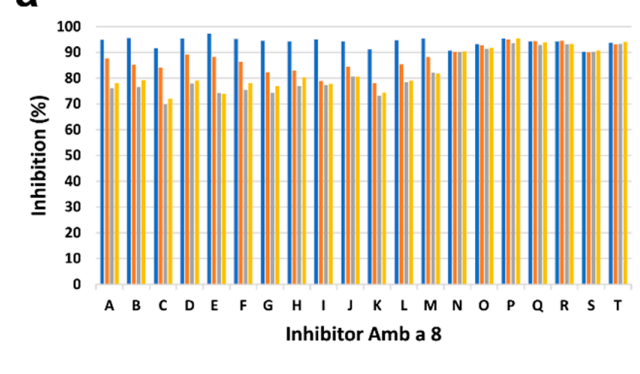

C

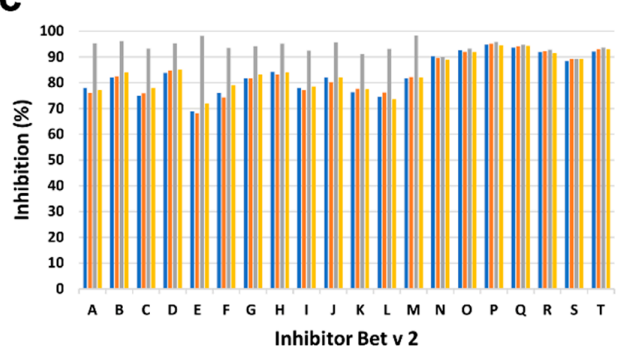

b

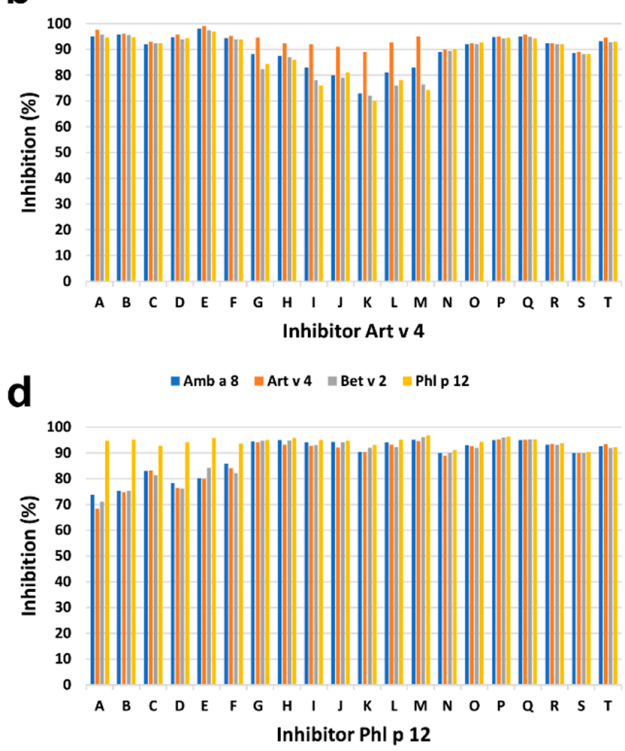

Figure 7. Results of ELISA inhibition assays, in which Amb a 8.0101 (a), Art v 4.0101 (b), Bet v 2.0101 (c), or Phl p 12.0101 (d) were used in increasing concentrations. Maximum inhibition of IgE binding by different profilins in individual patients is shown. Letters represent individual patients. Patients A-F: dominant IgE binding to Art v 4.0101; G-M: dominant IgE binding to Phl p 12.0101; N-T: no dominant IgE binding.

\section{Discussion}

Profilins are panallergens that are often associated with co-sensitization and various syndromes which arise due to the profilins' IgE cross-reactivity. Due to no reports of posttranslational modifications of allergenic profilins, these group of proteins can be efficiently produced in E. coli and used in a recombinant form for component-resolved allergy diagnostics. In addition, the recombinant version of these proteins can be used to determine sensitization patterns characteristic to various regions [20-22]. The use of recombinant profilins provides an opportunity for standardization of tests and eliminates problems associated with the low content of these allergens in some extracts $[23,24]$. At the same time, one has to take the relatively low stability of these proteins into account when storing the recombinant profilins or using them in solutions that have very low or very high $\mathrm{pH}$ values [10]. Here, we have demonstrated that $\mathrm{rPhl} \mathrm{p} 12.0101$ is significantly more stable than other pollen profilins and can be used in a relatively broad range of $\mathrm{pH}$ values. Therefore, this allergen seems to a be viable candidate for application in component-resolved allergy diagnostics.

The prevalence of sensitization to profilins in our population was similar to that reported previously in other populations of patients suffering from pollen allergy [22,25-27]. Sensitization to all studied profilins detected in each $\mathrm{P}+$ patient reflected high structural similarities and immune cross-reactivity among plant-derived profilins (Figure 2) [2]. However, the prevalence of IgE sensitization to different cross-reactive allergens is different in different populations and is influenced by several factors such as geographic factors, patient age, and sensitization patterns [22,25-28]. Interestingly, in one population of vegetable food-allergic patients in Italy, sensitization to profilins was as low as $11.7 \%$ [25]. On the other hand, others reported frequency of sensitization to profilins in children with pollen-food syndrome greater than $30 \%$ which was significantly greater than that in rhinoconjunctivitis without allergy to food [16]. Also, regarding geographic regions, a relevant north-south gradient in the frequency of pollen-food syndrome was seen with the greatest frequency reported in Northern regions in comparison to Southern Italy [26].

The presence of allergy to a given allergen source, such as birch or grass pollen, is associated with a different rate of sensitization to profilins [26-30]. In the already mentioned large Italian study, among 
patients with pollen-food syndrome, sensitization to Phl p 12 was significantly more prevalent in children allergic to melon and watermelon [26]. Allergy to different airborne allergens is also associated with different prevalence of sensitization to profilins [29,30]. Among patients sensitized to a date palm tree or a goosefoot pollen, IgE immune response to profilins (Pho d 2 and Che $\mathrm{d} 2$, respectively) is detected in more than $50 \%$ of patients which classifies these proteins as major allergens $[29,30]$. Association between sensitization to mugwort pollen and profilins has already been reported in adult patients in northern Europe [31]. In fact, we could also demonstrate more frequent sensitization to mugwort pollen in $\mathrm{P}+$ patients (not shown). Moreover, the greatest intensity of IgE ELISA to rArt $\mathrm{v} 4.0101$ seen in more than $30 \%$ of $\mathrm{P}+$ patients suggests that in some patients, the mugwort profilin may be the sensitizing one. In fact, this was supported by inhibition ELISA which demonstrated the greatest spectrum of Art $v 4$ epitopes recognized by IgE from those patients.

In a majority of patients sensitized to profilins, the greatest intensity of $\operatorname{IgE}$ binding was demonstrated for $\mathrm{rPhl} \mathrm{p}$ 12.0101. It has been proposed that sensitization to profilins depends on the intensity of exposure to individual allergen sources, and grass pollen is the one most important [21,32]. In some populations of birch and grass allergic patients, the frequency of sensitization to profilins in those allergic to birch was greater than to grass pollen $[27,28]$. Interestingly, in those populations from central Europe, sensitization to profilins was more frequently seen in children than in adults [27,28]. Another study demonstrated that in a cohort of birch pollen allergic children and adults, monosensitization to birch pollen, which is frequently associated with pollen-food syndrome, was not associated with greater frequency of sensitization to Bet $\mathrm{v} 2$ [33]. This observation is consistent with our results which indicate no association between sensitization to birch pollen and Bet $\mathrm{v} 2$ in a group of young children and adults with pollen-food syndrome. Moreover, sensitizations to profilins were reported to be associated with high or prolonged exposure to a given allergen source and often correlated with increased severity of the disease $[34,35]$.

Furthermore, there appears to be a correlation between age and profilin sensitization. For example, a longitudinal study of molecular spreading of sensitization to individual allergens in timothy grass allergic children demonstrated that IgE to profilins appears late and usually after sensitization to major allergens such as Phl p 1 and Phl p 5 is well developed [34]. The greatest frequency of sensitization to profilins was not achieved earlier than five years after the onset of clinical symptoms [34]. Similar observations concerning age and sensitization to profilins was made in a large population of Italian children with allergic rhinoconjunctivitis [22]. The sensitization rate to profilins was yet on the rise in allergic adolescents older than 15 years of age [22]. Moreover, clear association was demonstrated between sensitization to profilins and to the number of allergen sources including major tree, grass, and weed pollens [22]. However, in some populations of pollinosis patients older than eight years of age, no simple correlation between age and sensitization to Bet $\mathrm{v} 2$ could be demonstrated [35]. We could not find any association between clinical symptoms of pollen-allergy syndrome and sensitization to profilins (data not shown). This indicates that sensitization to profilins was not necessary for development of pollen-food syndrome in young children. Moreover, it indicates that the syndrome should be dependent on sensitization to other cross-reacting allergen components such as PR-10 allergens.

Interestingly, in some populations from southern Europe, higher prevalence of sensitization to profilins in patients with different forms of plant-derived food allergy, most frequently pollen-food syndrome, was demonstrated [36]. However, in central and northern Europe, sensitization to profilins did not correlate with food allergy in allergic adults [37,38]. Moreover, in southern Europe, sensitization to Bet $\mathrm{v} 2$ was not associated with pollen-food syndrome among birch allergic patients [33]. Furthermore, in those sensitized to Bet $\mathrm{v} 2$, pollen-food syndrome was seen less frequently than in patients sensitized to Bet v 1 [33]. Our results are consistent with those observations. However, it is of vital importance to note that exposure to food allergenic sources may participate in immune recognition of profilins. Profilins from both wheat (Tri a 12) and soy (Gly $\mathrm{m} 3$ ) have been described, and IgE immune response to Tri a 12 and Gly $\mathrm{m} 3$ have been documented in some populations of allergic patients [39-42]. Sensitization to Gly $\mathrm{m} 3$ was demonstrated in nearly $70 \%$ of patients allergic to soy products [42]. 
Further studies including ELISA inhibition assays with application of different pollen and food profilins may help to reveal a possible role of plant profilins in induction of IgE response in patients sensitized to those allergens.

\section{Materials and Methods}

\subsection{Production of Recombinant Profilins}

Recombinant rAmb a 8.0101, rArt v 4.0101, and rBet v 2.0101 were produced as described previously [2]. The gene coding for $\mathrm{rPhl} \mathrm{p} 12.0101$ was synthesized and inserted in pET26b plasmid and purchased from Bio Basic (Amherst, NY, USA). For easy purification by immobilized metal affinity chromatography (IMAC) using Ni-NTA, the Phl p 12.0101 construct was designed with a cleavable N-terminal 6X-polyhistidine tag, MHHHHHHSSGVDLGTENLYFQ!SGSG, where the exclamation mark shows the Tobacco Etch Virus (TEV) protease cleavage site. The newly synthesized plasmid was transformed into E. coli BL21(DE3) cells. A single colony was inoculated into $5.0 \mathrm{~mL}$ Lysogeny Broth starter culture supplemented with $100 \mathrm{mg}$ of glucose and $10 \mu \mathrm{L}$ of kanamycin at $50 \mathrm{mg} / \mathrm{mL}$ and grown with shaking $(250 \mathrm{rpm})$ overnight at $37^{\circ} \mathrm{C}$. One liter cultures were then grown in terrific broth with $50 \mu \mathrm{g} / \mathrm{mL}$ kanamycin at $37^{\circ} \mathrm{C}$ to an $\mathrm{OD}_{600}$ of 0.4 . The cultures were cooled to room temperature $\left(22^{\circ} \mathrm{C}\right)$ and grown to an $\mathrm{OD}_{600}$ of $0.8-1.0$, then induced with $0.5 \mathrm{mM}$ isopropyl $\beta$-D-1-thiogalactopyranoside (IPTG), cooled to $16{ }^{\circ} \mathrm{C}$, and grown overnight for protein expression.

After resuspending the cell pellets obtained from the $1.0 \mathrm{~L}$ cultures in lysis buffer $(50 \mathrm{mM}$ Tris- $\mathrm{HCl}$, $500 \mathrm{mM} \mathrm{NaCl}, 2 \%$ glycerol, $20 \mathrm{mM} \beta$-mercaptoethanol ( $\beta$-ME), $10 \mathrm{mM}$ imidazole, $\mathrm{pH} 7.4)$, the cells were lysed by sonication. The sonicated mixture was centrifuged at $9000 \times \mathrm{g}$ for $10 \mathrm{~min}$ at $4{ }^{\circ} \mathrm{C}$. The supernatant containing $\mathrm{Phl} p 12.0101$ was purified by IMAC using Ni-NTA. The protein was eluted using elution buffer ( $50 \mathrm{mM}$ Tris- $\mathrm{HCl}, 50 \mathrm{mM} \mathrm{NaCl}, 2 \%$ glycerol, $20 \mathrm{mM} \beta-\mathrm{ME}, 250 \mathrm{mM}$ imidazole, pH 7.4). SDS-PAGE was used to determine the elution fractions containing Phl p12.0101. Elution fractions containing protein were pooled and dialyzed overnight at $4{ }^{\circ} \mathrm{C}$ using Pierce SnakeSkin Dialysis Tubing with a molecular weight cut-off of $3000 \mathrm{Da}$ in dialysis buffer $(50 \mathrm{mM}$ Tris- $\mathrm{HCl}$, $150 \mathrm{mM} \mathrm{NaCl}, \mathrm{pH}$ 7.4). The dialyzed protein was concentrated using an Amicon Ultra centrifugal filter with 3000 Da molecular weight cut-off and further purified by size exclusion chromatography in the same buffer used in dialysis. Based on size exclusion chromatography, rPhl p 12.0101 was eluted in monomeric form. TEV protease was used to cleave the purification polyhistidine-tag when needed. After concentrating the protein, the concentration of rPhl p 12.0101 was determined at $280 \mathrm{~nm}$ using a Thermo-Scientific Nanodrop (extinction co-efficient of $18,450 \mathrm{~L} \mathrm{~mol}^{-1} \mathrm{~cm}^{-1}$, as determined by ProtParam; https://web.expasy.org/protparam/). The yield of $\mathrm{rPhl}$ p 12.0101 was $70 \mathrm{mg} / \mathrm{L}$ culture. To cleave the purification tag from the purified protein, TEV protease was used according to the protocol described previously [43].

\subsection{Differential Scanning Fluorimetry}

Differential scanning fluorimetry (DSF) is a very robust method to study the thermal stability of proteins. Profilins, as such, have been denoted as thermally labile [10]. To investigate the thermal stability of Phl p 12 with and without the purification tag, DSF was performed by using an in-house sodium chloride salt and $\mathrm{pH}$ gradient screen. All the solutions prepared and the steps followed during the experiment were carried out according to a previously published protocol [43].

Briefly, $50 \mathrm{mM}$ working concentration of buffer was used for all the conditions with a $\mathrm{pH}$ range of 4.0-9.5 (in 0.5 unit increments) and a salt range $(\mathrm{NaCl})$ of 0-1.0 M (no salt, 0.125, 0.250, 0.500, 0.625, 0.750, 0.875, and 1.000 M). The DSF experiments were done using Bio-Rad CFX96 RT-PCR instrument and the melting temperatures were determined by in Bio-Rad CFX Manager software. An average melting temperature $\left(\mathrm{T}_{\mathrm{m}}\right)$ for the protein was found by determining the inflection point of the melting curves generated by the software (in triplicates). The melting temperatures obtained for Phl p 12 were compared to previously determined melting temperatures for Amb a 8, Art v 4, and Bet v 2 [43]. 


\subsection{Spectroscopy}

Although thousands of crystallization conditions were tested to crystallize rPhl p 12.0101, no diffracting crystal has been obtained. To estimate the secondary structure of the protein, circular dichroism (CD) spectroscopy using the JASCO spectrophotometer was employed. rPhl p 12.0101 samples for CD experiments (without purification tag) were desalted using a prepacked Sephadex ${ }^{\mathrm{TM}}$ G25 column (GE Healthcare) with beads previously equilibrated in $10 \mathrm{mM}$ sodium phosphate buffer that had the $\mathrm{pH}$ adjusted to 7.4 using phosphoric acid. The samples were concentrated to $40 \mu \mathrm{M}$ following the same method as described above. The instrument was operated according to the manufacturer's protocol at a wavelength range of 220-320 nm. CAPITO software was used for data processing and the secondary structure percentages were calculated [19].

\subsection{Selection of Patients and Antibody Binding Studies}

One hundred allergic patients, including 50 children and 50 adults sensitized to pollen and plant-derived food allergens, were included. Patients with parasitic infection, autoimmune and systemic diseases, chronic respiratory diseases of non-allergic background, systemic steroids, or immunosuppressive therapy were excluded from the study. The included patients had never been treated with allergen immunotherapy before the study.

The sensitization was diagnosed by the assessment of specific $\operatorname{IgE}$ (sIgE) antibodies to individual allergen sources using a multiparameter immunoblot polycheck (Biocheck, GmbH, Münster, Germany) according to the manufacturer's protocol. Sensitization to individual components of birch and timothy grass pollens including Bet v 1, Bet v 2, Bet v 4, Bet v 6, Phl p 1, Phl p 5, Phl p 7, and Phl p 12 was determined using a multiparameter immunoblot (Euroline DPA-Dx Euroimmun, Lubecke, Germany) according to the manufacturer's protocol. The detection limit of the tests is $0.35 \mathrm{kU} / \mathrm{L} \mathrm{IgE;} \mathrm{measurable}$ specific IgE was defined as a positive test result if $>0.35 \mathrm{kU} / \mathrm{L}$.

All sera were also tested for IgE reactivity to a panel of recombinant pollen profilins $\mathrm{rAmb}$ a 8.0101, rArt v 4.0101, rBet v 2.0101, and rPhl p 12.0101 which previously had been structurally and immunologically characterized [5]. The proteins were used in an enzyme-linked immunosorbent assay (ELISA) as previously described [5]. Briefly, 96-well MaxiSorp microtiter plates (Nunc, Roskilde, Denmark) were coated with $100 \mu \mathrm{L}$ of rArt v 4.0101, rAmb a 8.0101, rPhl p 12.0101, or rBet v 2.0101 per well, each at a final concentration of $10 \mu \mathrm{g} / \mathrm{mL}$ diluted in coating $25 \mathrm{mM}$ carbonate/bicarbonate buffer $\mathrm{pH} 9.4$ and incubated overnight at $4{ }^{\circ} \mathrm{C}$. After washing with Tris-buffered saline supplemented with $0.05 \%$ Tween 20 (TBST) buffer, the plates were blocked with TBST $+1 \%$ bovine serum albumin (BSA) for $1 \mathrm{~h}$ at room temperature. For IgE ELISA, the plates were washed in TBST and patients' sera diluted in TBST $+1 \%$ BSA (1:5) were loaded on the plates and incubated for $2 \mathrm{~h}$ at room temperature. After the plates were thoroughly washed in TBST, a monoclonal anti-human IgE antibody conjugated to alkaline phosphatase diluted 1:1000 in TBST + 1\% BSA (BD Pharmingen, Heidelberg, Germany) was applied and incubated for $2 \mathrm{~h}$ at room temperature. Following washing, bound antibodies were detected by incubation with p-nitrophenyl phosphate (Sigma Fast p-nitrophenyl phosphate tablet sets, Sigma-Aldrich). The reaction was quantified by measuring color intensity at $405 \mathrm{~nm}$ and the results presented as optical density (OD). To evaluate specificity of the test in all experiments, negative controls were used and consisted of the following: no allergen immobilized on the plate, no serum applied, irrelevant allergen immobilized on the plate, or no anti-IgE added. All samples were run in triplicate, and the mean value was used for analysis. The cut-off for positive values was determined using the mean OD values of 10 non-allergic patients' sera plus three standard deviation (SD) values.

For the ELISA inhibition assay, in addition to regular ELISA performed as described above, patients' sera were pre-incubated for $30 \mathrm{~min}$ at RT with a serial 10-fold dilutions of inhibitory allergens dissolved in TBST $+1 \%$ BSA at concentrations up to $50 \mu \mathrm{g} / \mathrm{mL}$. The samples were then loaded on a plate and the procedure was continued as described for the ELISA assay above. 
The study was approved be the local Bioethics Committee (R-I-002/160/2016 and R-I-002/161/2016 for children and adults, respectively). The adult patients signed a written informed consent. The parents signed a written informed consent for their children to participate in the study.

\subsection{Statistical Analysis}

Statistical analysis was performed by using SPSS for Windows software (version 13.1; PL). The comparison of quantitative variables was carried out using the Student's t-test in case of normally distributed data and the Chi-squared and Mann-Whitney test in case of nonparametric data. A $p$-value $<0.05$ was considered statistically significant. For correlation analysis, Spearman correlation test was applied.

\section{Conclusions}

In summary, our study demonstrates that the presence of $\operatorname{IgE}$ to profilins in patients with pollen-food syndrome is quite frequent. However, no clinical significance of that sensitization among patients living in the area where birch pollen is a dominant tree allergen source could be demonstrated. Ragweed is not present in the North-East Poland, but we observed reaction to rAmb a 8.0101. This is caused by the high sequence and structure similarity between the profilin originating from ragweed and other studied profilins. Further studies are warranted to clarify the role of individual allergen sources in the process of sensitization to individual proteins among allergic patients exposed to different aeroallergens.

Author Contributions: B.C., M.C., K.K., and D.M.L. designed the study; B.C., M.C., A.B.K., K.K., and D.M.L. wrote the manuscript; B.C., M.P., A.P., A.B.K., N.H., S.P., and C.R.S. contributed to data collection; B.C., K.K., and M.C. performed the statistical analysis and interpretation of the results. All authors have read and agreed to the published version of the manuscript.

Funding: The study was supported by N/ST/ZB/17/004/1143 grant from the Medical University of Bialystok. M.C., A.B.K. and C.R.S. were partially supported by R01AI077653 grant from National Institute of Allergy and Infectious Diseases. The content is solely the responsibility of the authors and does not necessarily represent the official views of the National Institutes of Health.

Conflicts of Interest: B.C., A.B.K., M.P., A.P., N.H., S.P., C.R.S., M.C., and D.M.L. declare no conflict of interest. K.K. received lecture fees from: ALK Abello, Astra Zeneca, Berlin Chemie, Chiesi, Emma, Hal Allergy, Meda Pharma, Orion Pharma, and royalties from UpToDate.

\section{References}

1. McKenna, O.E.; Asam, C.; Araujo, G.R.; Roulias, A.; Goulart, L.R.; Ferreira, F. How relevant is panallergen sensitization in the development of allergies? Pediatr. Allergy Immunol. 2016, 27, 560-568. [CrossRef]

2. Offermann, L.R.; Schlachter, C.R.; Perdue, M.L.; Majorek, K.A.; He, J.Z.; Booth, W.T.; Garrett, J.; Kowal, K.; Chruszcz, M. Structural, functional, and immunological characterization of profilin panallergens Amb a 8, Art v 4, and Bet v 2. J. Biol. Chem. 2016, 291, 15447-15459. [CrossRef]

3. Carlsson, L.; Nyström, L.-E.; Sundkvist, I.; Markey, F.; Lindberg, U. Actin polymerizability is influenced by profilin, a low molecular weight protein in non-muscle cells. J. Mol. Biol. 1977, 115, 465-483. [CrossRef]

4. Chruszcz, M.; Kapingidza, A.B.; Dolamore, C.; Kowal, K. A robust method for the estimation and visualization of IgE cross-reactivity likelihood between allergens belonging to the same protein family. PLoS ONE 2018, 13, e0208276. [CrossRef] [PubMed]

5. Hauser, M.; Roulias, A.; Ferreira, F.; Egger, M. Panallergens and their impact on the allergic patient. Allergy Asthma Clin. Immunol. 2010, 6, 1-14. [CrossRef] [PubMed]

6. Feliu, A.; Gonzalez-de-Olano, D.; Gonzalez, E.; Rodriguez, B.; Ruiz-Hornillos, J.; Jimeno, L.; de la Torre, F. A multicenter study of sensitization profiles in an allergic pediatric population in an area with high allergen exposure. J. Investig. Allergol. Clin. Immunol. 2013, 23, 337-344.

7. Worm, M.; Jappe, U.; Kleine-Tebbe, J.; Schafer, C.; Reese, I.; Saloga, J.; Treudler, R.; Zuberbier, T.; Wassmann, A.; Fuchs, T; et al. Food allergies resulting from immunological cross-reactivity with inhalant allergens: Guidelines from the German Society for Allergology and Clinical Immunology (DGAKI), the German 
Dermatology Society (DDG), the Association of German Allergologists (AeDA) and the Society for Pediatric Allergology and Environmental Medicine (GPA). Allergo J. Int. 2014, 23, 1-16. [PubMed]

8. Alvarado, M.I.; Jimeno, L.; De La Torre, F.; Boissy, P.; Rivas, B.; Lazaro, M.J.; Barber, D. Profilin as a severe food allergen in allergic patients overexposed to grass pollen. Allergy 2014, 69, 1610-1616. [CrossRef]

9. Ruiz-Garcia, M.; Garcia Del Potro, M.; Fernandez-Nieto, M.; Barber, D.; Jimeno-Nogales, L.; Sastre, J. Profilin: A relevant aeroallergen? J. Allergy Clin. Immunol. 2011, 128, 416-418. [CrossRef]

10. Kapingidza, A.B.; Pye, S.E.; Hyduke, N.; Dolamore, C.; Pote, S.; Schlachter, C.R.; Commins, S.P.; Kowal, K.; Chruszcz, M. Comparative structural and thermal stability studies of Cuc m 2.0101, Art v 4.0101 and other allergenic profilins. Mol. Immunol. 2019, 114, 19-29. [CrossRef]

11. Valenta, R.; Duchene, M.; Ebner, C.; Valent, P.; Sillaber, C.; Deviller, P.; Ferreira, F.; Tejkl, M.; Edelmann, H.; Kraft, D.; et al. Profilins constitute a novel family of functional plant pan-allergens. J. Exp. Med. 1992, 175, 377-385. [CrossRef] [PubMed]

12. Gadermaier, G.; Hauser, M.; Ferreira, F. Allergens of weed pollen: An overview on recombinant and natural molecules. Methods 2014, 66, 55-66. [CrossRef] [PubMed]

13. Asero, R.; Wopfner, N.; Gruber, P.; Gadermaier, G.; Ferreira, F. Artemisia and ambrosia hypersensitivity: Co-sensitization or co-recognition? Clin. Exp. Allergy 2006, 36, 658-665. [CrossRef]

14. Valenta, R.; Duchene, M.; Pettenburger, K.; Sillaber, C.; Valent, P.; Bettelheim, P.; Breitenbach, M.; Rumpold, H.; Kraft, D.; Scheiner, O. Identification of profilin as a novel pollen allergen; IgE autoreactivity in sensitized individuals. Science 1991, 253, 557-560. [CrossRef]

15. Fedorov, A.A.; Ball, T.; Mahoney, N.M.; Valenta, R.; Almo, S.C. The molecular basis for allergen cross-reactivity: Crystal structure and IgE-epitope mapping of birch pollen profilin. Structure 1997, 5, 33-45. [CrossRef]

16. Lund, G.; Brand, S.; Ramos, T.; Jimeno, L.; Boissy, P.; Vega, F.; Arina, M.; Christensen, L.H.; Hoof, I.; Meno, K.H.; et al. Strong and frequent T-cell responses to the minor allergen Phl p 12 in Spanish patients IgE-sensitized to Profilins. Allergy 2018, 73, 1013-1021. [CrossRef]

17. Sievers, F.; Wilm, A.; Dineen, D.; Gibson, T.J.; Karplus, K.; Li, W.; Lopez, R.; McWilliam, H.; Remmert, M.; Söding, J. Fast, scalable generation of high-quality protein multiple sequence alignments using Clustal Omega. Mol. Syst. Biol. 2011, 7, 539. [CrossRef]

18. Gouet, P.; Robert, X.; Courcelle, E. ESPript/ENDscript: Extracting and rendering sequence and 3D information from atomic structures of proteins. Nucleic Acids Res. 2003, 31, 3320-3323. [CrossRef]

19. Wiedemann, C.; Bellstedt, P.; Görlach, M. CAPITO—A web server-based analysis and plotting tool for circular dichroism data. Bioinformatics 2013, 29, 1750-1757. [CrossRef]

20. Asero, R.; Monsalve, R.; Barber, D. Profilin sensitization detected in the office by skin prick test: A study of prevalence and clinical relevance of profilin as a plant food allergen. Clin. Exp. Allergy 2008, 38, 1033-1037. [CrossRef]

21. Barber, D.; De La Torre, F.; Lombardero, M.; Antepara, I.; Colas, C.; Dávila, I.; Tabar, A.; Vidal, C.; Villalba, M.; Salcedo, G. Component-resolved diagnosis of pollen allergy based on skin testing with profilin, polcalcin and lipid transfer protein pan-allergens. Clin. Exp. Allergy 2009, 39, 1764-1773. [CrossRef] [PubMed]

22. Asero, R.; Tripodi, S.; Dondi, A.; Businco, A.D.R.; Sfika, I.; Bianchi, A.; Candelotti, P.; Caffarelli, C.; Dascola, C.P.; Ricci, G. Prevalence and clinical relevance of IgE sensitization to profilin in childhood: A multicenter study. Int. Arch. Allergy Immunol. 2015, 168, 25-31. [CrossRef] [PubMed]

23. Asero, R.; Mistrello, G.; Amato, S. Detection of pan-allergens in commercial pollen extracts for allergen immunotherapy. Ann. Allergy, Asthma Immunol. 2016, 117, 180-185. [CrossRef] [PubMed]

24. Pitsios, C.; Iliopoulou, A.; Kontogianni, M.; Papagregoriou, G. Detection of profilin in SPT extracts that are supposed to contain it. Allergol. Immunopathol. 2019, 47, 12-15. [CrossRef]

25. Nucera, E.; Mezzacappa, S.; Aruanno, A.; Pecora, V.; Rizzi, A.; Ricci, A.G.; Ferraironi, M.; Buonomo, A.; Schiavino, D. Hypersensitivity to major panallergens in a population of 120 patients. Adv. Dermatol. Allergol./Postępy Dermatol. Alergol. 2015, 32, 255. [CrossRef]

26. Mastrorilli, C.; Tripodi, S.; Caffarelli, C.; Perna, S.; Di Rienzo-Businco, A.; Sfika, I.; Asero, R.; Dondi, A.; Bianchi, A.; Povesi Dascola, C. Endotypes of pollen-food syndrome in children with seasonal allergic rhinoconjunctivitis: A molecular classification. Allergy 2016, 71, 1181-1191. [CrossRef]

27. Sekerkova, A.; Polackova, M.; Striz, I. Detection of Phl p 1, Phl p 5, Phl p 7 and Phl p 12 specific IgE antibodies in the sera of children and adult patients allergic to Phleum pollen. Allergol. Int. 2012, 61, 339-346. [CrossRef] 
28. Sekerková, A.; Poláčková, M. Detection of Bet v1, Bet v2 and Bet v4 specific IgE antibodies in the sera of children and adult patients allergic to birch pollen: Evaluation of different IgE reactivity profiles depending on age and local sensitization. Int. Arch. Allergy Immunol. 2011, 154, 278-285. [CrossRef]

29. Asturias, J.; Ibarrola, I.; Fernandez, J.; Arilla, M.; Gonzalez-Rioja, R.; Martinez, A. Pho d 2, a major allergen from date palm pollen, is a profilin: Cloning, sequencing, and immunoglobulin E cross-reactivity with other profilins. Clin. Exp. Allergy 2005, 35, 374-381. [CrossRef]

30. Barderas, R.; Villalba, M.; Pascual, C.Y.; Batanero, E.; Rodríguez, R. Profilin (Che a 2) and polcalcin (Che a 3) are relevant allergens of Chenopodium album pollen: Isolation, amino acid sequences, and immunologic properties. J. Allergy Clin. Immunol. 2004, 113, 1192-1198. [CrossRef]

31. Movérare, R.; Larsson, H.; Carlsson, R.; Holmquist, I. Mugwort-sensitized individuals from North Europe, South Europe and North America show different IgE reactivity patterns. Int. Arch. Allergy Immunol. 2011, 154, 164-172. [CrossRef]

32. Barber, D.; Díaz-Perales, A.; Villalba, M.; Chivato, T. Challenges for allergy diagnosis in regions with complex pollen exposures. Curr. Allergy Asthma Rep. 2015, 15, 496. [CrossRef]

33. Rossi, R.; Monasterolo, G.; Operti, D.; Corsi, M. Evaluation of recombinant allergens Bet v 1 and Bet v 2 (profilin) by Pharmacia CAP System in patients with pollen-related allergy to birch and apple. Allergy 1996, 51, 940-945. [CrossRef] [PubMed]

34. Hatzler, L.; Panetta, V.; Lau, S.; Wagner, P.; Bergmann, R.L.; Illi, S.; Bergmann, K.E.; Keil, T.; Hofmaier, S.; Rohrbach, A. Molecular spreading and predictive value of preclinical IgE response to Phleum pratense in children with hay fever. J. Allergy Clin. Immunol. 2012, 130, 894-901. e5. [CrossRef] [PubMed]

35. Daschner, A.; Crespo, J.F.; Pascual, C. Specific IgE to recombinant vegetal panallergen (rBet v 2) and fruit allergy in pollinic patients. Allergy 1998, 53, 614-618. [CrossRef] [PubMed]

36. Barber, D.; De La Torre, F.; Feo, F.; Florido, F.; Guardia, P.; Moreno, C.; Quiralte, J.; Lombardero, M.; Villalba, M.; Salcedo, G. Understanding patient sensitization profiles in complex pollen areas: A molecular epidemiological study. Allergy 2008, 63, 1550-1558. [CrossRef] [PubMed]

37. San Nicoló, M.; Braun, T.; Eder, K.; Berghaus, A.; Gröger, M. Clinical relevance of IgE to profilin and/or polcalcin in pollen-sensitized patients. Int. Arch. Allergy Immunol. 2016, 169, 101-107. [CrossRef] [PubMed]

38. Geroldinger-Simic, M.; Zelniker, T.; Aberer, W.; Ebner, C.; Egger, C.; Greiderer, A.; Prem, N.; Lidholm, J.; Ballmer-Weber, B.K.; Vieths, S. Birch pollen-related food allergy: Clinical aspects and the role of allergen-specific IgE and IgG4 antibodies. J. Allergy Clin. Immunol. 2011, 127, 616-622. e1. [CrossRef]

39. Cichna-Markl, M.; Forstenlechner, P.; Hoffmann-Sommergruber, K.; Milić, D.; Matković-Čalogović, D.; Ecker, C. Expression, purification and crystallization of wheat profilin (Tri a 12). Clin. Transl. Allergy 2011, 1, P4. [CrossRef]

40. Olivieri, M.; Biscardo, C.A.; Palazzo, P.; Pahr, S.; Malerba, G.; Ferrara, R.; Zennaro, D.; Zanoni, G.; Xumerle, L.; Valenta, R. Wheat IgE profiling and wheat IgE levels in bakers with allergic occupational phenotypes. Occup. Environ. Med. 2013, 70, 617-622. [CrossRef]

41. Amnuaycheewa, P.; de Mejia, E.G. Purification, characterisation, and quantification of the soy allergen profilin (Gly m 3) in soy products. Food Chem. 2010, 119, 1671-1680. [CrossRef]

42. Rihs, H.-P.; Chen, Z.; Ruëff, F.; Petersen, A.; Rozynek, P.; Heimanna, H.; Baur, X. IgE binding of the recombinant allergen soybean profilin (rGly $\mathrm{m} 3$ ) is mediated by conformational epitopes. J. Allergy Clin. Immunol. 1999, 104, 1293-1301. [CrossRef]

43. Booth, W.T.; Schlachter, C.R.; Pote, S.; Ussin, N.; Mank, N.J.; Klapper, V.; Offermann, L.R.; Tang, C.; Hurlburt, B.K.; Chruszcz, M. Impact of an N-terminal polyhistidine tag on protein thermal stability. ACS Omega 2018, 3, 760-768. [CrossRef] [PubMed]

Sample Availability: Plasmids with genes coding for the described here profilins are available from the authors upon request.

(C) 2020 by the authors. Licensee MDPI, Basel, Switzerland. This article is an open access article distributed under the terms and conditions of the Creative Commons Attribution (CC BY) license (http://creativecommons.org/licenses/by/4.0/). 